\title{
Camel Milk: Massive Paragon of Nutritional and Therapeutic Potentials: A Review
}

\author{
Adnan Khaliq ${ }^{1 *}$, Muhammad Farhan Jahangir Chughtai ${ }^{1}$, Muhammad Nadeem ${ }^{3}$, Ayesha \\ Aslam $^{2}$, Atif Liaqat ${ }^{1}$, Tariq Mehmmod ${ }^{1}$, Samreen Ahsan ${ }^{2}$ \\ ${ }^{I}$ Department of Food Science and Technology, Khwaja Fareed University of Engineering \& Information \\ Technology, Rahim Yar Khan-Pakistan. \\ ${ }^{2}$ Faculty of Food Nutrition and Home Sciences, National Institute of Food Science andTechnology, University \\ of Agriculture Faisalabad-Pakistan. \\ ${ }^{3}$ Department of Environmental Sciences, COMSATS University Islamabad, Vehari Campus-Pakistan.
}

*Corresponding Author: Adnan Khaliq, Department of Food Science and Technology, Khwaja Fareed University of Engineering \& Information Technology, Rahim Yar Khan-Pakistan.

\begin{abstract}
Camels as a livestock play an amazing role in arid, semi-arid and particularly desert areas. Its milk obliges as a fundamental chunk of their daily needs. Globally,25.89 million camels are reported, 89\% of which are one humped and rest $11 \%$ are two humped. Arid regions of North East African countries own more than 60\% population of dromedary camels while Ethiopia ranks third in terms of population being second in camel milk production around the globe. Scientists recommended camel milk as white gold of the desert habituates, with potential similarities to human milk. It varies from other animals' milk as it contains low cholesterol, sugar, higher contents of inorganic constituents, vitamin C, protective proteins like lactoferrin, lacto peroxidase, lysozymes and immunoglobulins. It lacks in $\beta$-lactoglobulin but owns anti-oxidative, anticancer, antibacterial, antifungal, anti-hepatic properties. $\beta$-lactoglobulin also provides anti-ageing, antiarthritis, anti-tuberculosis and works as a tonic for many autoimmune diseases. The level of insulin in an approx. liter of camel milk is about 52 units, which is the highest amount of insulin when compared to other milk species, considered in improving long-term glycemic control in diabetic patients as well. A unique property of camel milk insulin, is its resistance to degradation even in the acidic environment of stomach unlike human, cow and goat milk. Camel milk reduces autism spectrum disorder in children. The lactoferrin acts as a multi-functional protein including the strong pathological effects and ability to inhibit the proliferation of cancer cells. Camel milk possesses antiulcer potential; reason is higher concentration of magnesium and zinc. Furthermore, a-hydroxyl acids in camel milk demonstrates anti-aging effects by removing outer dead cells of skin (epidermis) which assists in glowing smoothness of skin. Despite of such nutritional values,it is restricted to production areas due to certain factors like taste difference, inaccessibility to local market by middle man and dairy processors. Effective steps must be taken to propagate and to sensitize the prospective health dolesamongst the masses.
\end{abstract}

Keywords: Camel milk, Protective proteins, autoimmune disease, Fantabolous, disseminate, sensitize, benefits.

\section{INTRODUCTION}

Rendering to Food and Agriculture Organization (2013) 25.85 million camels are prevailing on the globe and out of which $89 \%$ are one humped and rest of the $11 \%$ are two humped camels. Regarding distribution of camel population, only 6 million are Camelusbactrianusand 19 million are one humped camel. One humped Dromedary (Camelusdromedarius) which accounts major portion of the total camel population on earth and mainly found in Arabian deserts, Central \& South Asia, and Afghanistan. Bactrian (Camelusbactrianus), two-humped camels, mostly found in China, Russia and some areas of Asia. Out of total population of African camels, $70 \%$ were found in Sudan, Somalia and Ethiopia whereas; other African countries added 12\% of the population(Kula and Tegegne, 2016). The dessert communities of Asia and Africa rely on camel for food; hauling and disease medicament from venerable times(Gader and Alhaider, 2016).Nature has blessed camels with peculiar traits, that they can produce milk in harsh environments for longer period of time, when compared to other 
livestock species(Ahmed et al., 2010). The milking capacity of a well-fed camel with good optimum condition is 3 to $10 \mathrm{~kg} /$ day, in lactation period of 1.5 year(Gizachew et al., 2014a). Somalia is a prominent county in terms of camel population followed by Ethiopia, with $2^{\text {nd }}$ largest camel milk production of 75,000 tons per annum approximately (Asresie and Yusuf, 2014).

Camel milk is considered as Nature's pharmacy and retains similarities to human milk, as compared to other milch animals, because it comprehends low cholesterol, low sugar, high minerals (Sodium, magnesium, potassium, zinc, iron and copper), 3 to 5 times more vitamin $\mathrm{C}$, defensive proteins such as lactoperoxidase, lysozymes, immunoglobulins and iron binding protein lactoferrin(Yadav et al., 2015).Counter effect of raw and fermented camel milk against various series of diseases such as stomach ulcer, colonic disorders, Diabetes-I, asthma, food allergy, dropsy, jaundice, leishmaniasis or kala-azar and hepatitis, has been reported well. Scientists have reported its usage to reduce blood cholesterol level(Ali et al., 2017) growth of cancer cells(Habib et al., 2013), evade psoriasis disease, heal inflammation, support tuberculosis cure, reinforce immune system(Asresie and Yusuf, 2014)and address autism spectrum disorder(Sharma and Singh, 2014).

Camel milk holds a small amount of $\beta$-casein and lacks $\beta$-Lactoglobulin (Konuspayeva et al., 2009). $\beta$-lactoglobulin is a whey protein, responsible for allergic action in human and $\beta$-caseins sometimes causes hypersensitivity in individuals. Camel milk lacks in allergic actions due to absence of $\beta$ lactoglobulin and different structure $\beta$-caseins as compared to bovine milk. Camel milk supplementation improves severe allergic problems rapidly in newborns (Gizachew et al., 2014a). The evidence of camel milk's therapeutic potential against many viral and infectious diseases has been identified (Asresie and Yusuf, 2014). Camels consume dessert plants while grazing, resulting in having medicinal properties against many diseases sourced from plants. Seifu (2007) reported that camel milk has been used by a large number of people for curing several ailments e.g. jaundice, malaria, constipation, clearing the stomach, post-partum care of women, detoxifying snake venom and alleviating flatulence. Recent studies confirmed that camel milk contains several protective proteins having bactericidal, fungicidal and viricidal properties (Mona et al., 2010), that strengthen the host's immune system, prevent microbial growth in gut and participates in primary immune system based on targeting of structures common to invade pathogens (Conesa et al., 2008). Peptides and proteins have shown biological activities on host's immune system by targeting and invading pathogens. These activities exert beneficial effect on many bioprocesses such as digestion, absorption, growth and immunity (Omer and Eltinay, 2008). Also, camel milk acquires more shelf life and can be stored at room temperature for longer periods, than milk from other animals (Yassin et al., 2015).

The consumption of camel milk has been increased worldwide due to considerable health benefits. It possesses tremendous therapeutic properties against different lifestyle related disorders. Hence, potential health benefits of camel as strong anti-oxidant, bactericidal, veridical, fungicidal and anticarcinogenic properties have been endorsed by several investigations (Al-Juboori et al., 2013; Sharma and Singh, 2014).

Keeping in mind the potential health benefits, nutritional, medicinal, pharmaceutical importance, it must be sensitized and its prominence must be disseminated among the masses. Hence in the line with the overhead, the intentions of this review paper are: -

a. To critically review of prevailing truths and scientific knowledge on biochemical configuration and therapeutic beliefs of camel milk.

b. To endorse advance enquiry on medicinal aspects of camel milk in international scientific community to pay attention on advance farm management practices for more milk production in camels

\section{CAMEL AND ITS SOCIO-ECONOMIC IMPORTANCE}

Camels are used for several socio-economic benefits for the mankind in one way or the other. For the last few years the industry related to camel is gaining remarkable importance around the globe. The first camel dairy farm was settled about 10 years ago in Middle East region particularly United Arab Emirates. Several studies and researches have started on the characteristics of camel and its different attributes for commercialization (Nagy and Juhasz, 2016).

Camels are primarily domesticated under severe condition for milk production and other uses. In remote and boarder areas army uses camels as animal for carrying burden and transfer heavy stuffs 
from one place to another. Now camels are not considered as the animals of old era,instead they are considered as the animal of struggle worldwide, with increasing desertification. Furthermore, they are used as a food for millions of individuals who are starving, due to adverse climate changes. Camel is preferred for obtaining milk as it can produce milk even in harsh climates, where the survival of other animals is questioned. Medicinal properties of camel milk are of major importance in the urban areas and now its consumption (due to its therapeutic properties) is enhanced. Camels share about $2 \%$ of the world's total milk production and a part of which is consumed usually by local pastoral people (Raziq et al., 2008).

The nature has provided a specific character in this animal,allowing it to survive in harsh conditions of water scarcity, hence gaining socio-economic values. Camels are extensively adaptive to the harsh temperature and drought conditions, where other animals cannot survive and provide milk with special properties where endurance of other animal's breeds is not easy and consume horny shrubs, thorny bushes and wild plants, unlike other species. The communities rearing camels use it for multiple purposes e.g. ploughing, leveling their fields, transportation (agricultural commodities, fuel, salt, wood etc.), as a power source for oil extraction, sugar cane crushing, grinding of wheat, corns and other grains. Camel has ability to carry about 250-300 kg transportation luggage, covering the distance of $25-30 \mathrm{~km}$ in five hours with unique capability to survive in harsh conditions (Shuiep et al., 2014). The desert communities of Asia and Africa rely on camel for food; hauling and disease medicament from venerable times (Gader and Alhaider, 2016). In arid and grim climate, camel produces more quantity of milk compared to other domestic milking animals with an average amount of 2000 to $4000 \mathrm{~L}$ in $12-18$ months of lactation period(Worku, 2015).

In Pakistan, one humped camelis in majority, the dromedary type, with a population of around 1 million, while there is very low population of two humped camels (approximately 1000 animals) present in northern areas of Pakistan and are kept in the zoos. In consideration of global warming concept and aridity environment, camel is the potential breed which is trusty and can alleviate our endeavor in food and nutrition dilemma. Current farming performances can be improved the life and commercial position of herdsman in Pakistan by handsome economic returns (amount of 0.1-0.2 million/animal). Besides milk and meat, camel belongings (hair and hide) are being used for manufacturing a variety of household products (hand bags, light lamps, ropes, tent clothes, shoes, door mats, saddlers \& blankets) and ornamental products (Faraz et al., 2013). In the backward areas of Pakistan with extreme weather conditions people rely only on camel for milk and meat. Despite several benefits of camel milk and meat, contribution of the camel milk in agricultural economy of Pakistan is not well recognized. Camels can contribute a significant role in socio-economics of the native deprived population. Local non-government organizations should play their role in these areas to improve camel milk production, livestock, and dairy development.

\subsection{Camel Milk Production}

Globally, camel ranks fifth among dairy animals on the basis of milk production after buffalo, cow, sheep and goat.As reported by FAO (2012), camel contributes $0.23 \%$ in the total amount of milk consumed. Africans countries fulfill $10 \%$ of their milk needs from the dromedary camels (Faye and Konuspayeva, 2012). Nevertheless, the exact amount of camel milk production is about 5.4 million tons annually as reported for African areas. During the past 48 years, the production of camel milk (Faye and Bonnet, 2012)increases with 2.45\% rate and the amount reaches $2.6 \%$ in the year 2008 (Nagy and Juhasz, 2016). The milking capacity of a well-fed camel with good optimum condition is 3 to $10 \mathrm{~kg}$ per day in lactation period of 1.5 year. One humped camels of Pakistan are recognized all over the world for their milk production capability. The maximum milk production is reported by Marecha breed with 4179L milk yield annually with a milking period of 275 to 545 days. In terms of milk production and lactation period Pakistani camels are regarded as world's best camel with the average milk production of 1300 to 4200 liters per year (India 2482; Somalia 1825; Tunisia and Algeria 1460; Ethiopia 1825). In Pakistan an average daily milk yield is $8 \mathrm{Kg} /$ animal (India 6.8; Somalia 5; Tunisia and Algeria 4; Ethiopia 5) whereas; Pakistani camel has ability to produce 15-20L/ day (Khan et al., 2016).

The shelf stability of camel milk is higher as compared to the others milk even at high temperature because of lactoferrin and others anti-microbial properties. Hence, the marketing of camel milk is quite easier than cow and buffalo milk, by maintaining the basic hygiene practices (Yaqoob and 
Nawaz, 2007). Researchers revealed that the young calf consumed 5 to $10 \mathrm{~L}$ of milk during the first 15 days of postpartum. The milking potential of camel is higher at the start of lactation like all other species (Sisay and Awoke, 2015).

The fluctuations observed in camel milk yield are due to management practices, ecology and traits differences. Other reasons are breeding of camels to calve after every two years along with the extended lactation periods, which are more pronounced under good nutritional levels. It has also been observed that on the rare occasions when camels calve every year a lactation period of 7 months is normal. Generally, lactation period and milking frequency of camel varies around the world depending upon the region, species, age and management practices (Sisay and Awoke, 2015). Camel produces about 0.6 million tons of milk yearly, with respect to butter production from camel milk, it is more than that of native dairy breeds of buffalo and cattle. Variety of world's camel breeds are reported in aridity and semi-arid areas of Pakistan. Massive yield differences are observed among the individuals of even same area and breed. It is now required to work over the management of genetic resource and its transformation in a proper way (Raziq et al., 2008).

\subsection{Health Benefits of Camel Milk}

Camel milk is well documented for medicinal health benefits due to its unique composition and nutritional properties since ancient times. It can play a vital role in the socio-economic progress of Pakistan (Faye, 2016). Worldwide, it is considered as a primary food especially in arid and semi-arid area. The milk strongly shows antimicrobial and antiviral properties having biological activity (bioactive compound Lactoferrin: LF) against food borne pathogens, act as anti-carcinogenic and prevents milk from spoilage (Abbas et al., 2013).

It is nutritionally balanced and easy to digest because of its natural homogenization. Camel milk contains higher amount of lactoferrin than other milks. Researchers suggested camel milk as white gold of the desert habituates with potential similarities to human milk. It owns various protective proteins like lactoperoxidase, lysozymes, lactoferrin and immunoglobulins with more anti-oxidant potential as compared to other milk sources (Rasheed, 2017; Kalla et al., 2017).

Lactoferrin (LF) and serum albumin contents in the camel milk are in range of about $(0.43 \%)$ and serum albumin $(0.34 \%)$ of total protein in the milk. LF is most important iron-binding glycoprotein of the camel milk having antimicrobial and antiviral nature. Different in vitro studies have been conducted to verify the ability of LF to lower the proliferation of cancer cells especially colorectal cancer cells (Habib et al., 2013).

Other workers concluded that the bioactive components of milk whey lactoferrin (LF) and immunoglobulin $\mathrm{G}$ (minor protein) are found in higher quantity in camel milk. Mean values are 0.229 $\pm 0.135 \mathrm{mg} / \mathrm{mL}$ for $\mathrm{LF}$ and $0.718 \pm 0.330 \mathrm{mg} / \mathrm{mL}$ for immunoglobulin $\mathrm{G}$ concentrations in raw camel milk. The reason of this variation is season; LF showing highest values in spring while immunoglobulin $\mathrm{G}$ showing highest value in winter (Konuspayeva et al., 2007). Large amount of minerals and vitamin $\mathrm{C}$ are present in it. Immunoglobulins of small size are found in high amounts that enhances the immunity of animal. The level of insulin is about 52 units approximately in a liter of milk. Different proteins and enzymes in camel milk exhibited immunological and antibacterial behavior during different studies (Mullaicharam, 2014).

\section{Physicochemical and Compositional Characteristics of Camel Milk}

It is essentially required to characterize the milk from any source because of its impact on the final product quality. The camel milk is opaque white in color due to the tiny fat globules with slight sweet and salty taste (Abbas et al., 2013). The composition of milk is governed by a number of factors like rearing conditions, water consumption and the diet of an animal (Yadav et al., 2015).

The studies reported that density of camel milk ranges from 1.027-1.036 whereas, $\mathrm{pH}$ from 6.3 to 6.6 lower as compared to cow's milk. Maximum buffering capacity is observed at $\mathrm{pH} 4.95$ of skim milk (Gul et al., 2015a) alongside, variations occur due to environment, feeding conditions, physiological stage, season, genetic makeup and individual animal health (Konuspayeva et al., 2009). Generally, camel milk contains $3.5 \%$ protein, $0.78 \%$ ash, $4.4 \%$ lactose, $3.4 \%$ fat and $87 \%$ water (Al Kanhal, 2010). Another study was carried out in Cholistan dessert on one humped camel's milk and average values were observed as $\mathrm{pH} 6.63$; acidity $0.15 \%$, total solids (TS) $10.9 \%$, solid not fat (SNF) $7.8 \%$, fat 
$3.2 \%$, lactose $3.97 \%$, ash $0.75 \%$, protein $3.07 \%$ and non-casein $0.747 \%$. However, the composition varied with seven days' periodic analysis for nine weeks (Abbas et al., 2013).

The composition of camel milk is reported by various scientists.(Konuspayeva et al., 2009) summarized the data from different papers and reported a significant difference in camel milk composition of Bactrian and Dromedary camels. The variation was observed in main factors like fat, total protein, lactose, dry matter and ash. The compositional analysis of camel milk reported by (Khaskheli et al., 2005) showed huge variation regarding the quality of raw camel milk in Punjab, with an increase of human population, food security issue arising significantly. To face these challenges, new resources for the production and consumption of food should be revealed. One humped camel are the perfect substitute and appropriate addition in the food supply chain with multipurpose benefits of milk, meat, skin and lots of other useful products stated above.

Various researchers reported the diversity in camel milk composition due to multiple factors like ecology, season, genetic makeup, animal health, feeding pattern and the breed. The variations in chemical composition of camel milk by different researchers are shown in following Table

\section{Composition OF CAMEL MiLK Reported by VARIOUS RESEARCHERS}

\subsection{Camel Milk Proteins}

The proteins contents of camel milk ranged between 2 to $4 \%$ however, variation has been observed with breed, feed, season and environmental conditions. The highest amount is observed in the month of December $(2.9 \%)$ and lower $(2.48 \%)$ in august (Konuspayeva et al., 2009). The camel milk proteins distributed in three main classes known as caseins, whey proteins and milk fat globule membrane proteins as discussed below.

\begin{tabular}{|l|l|l|l|l|}
\hline Authors & Fat (\%) & Protein (\%) & Lactose (\%) & Total solids (\%) \\
\hline (Shuiep et al., 2014) & 2.64 & 2.93 & 3.12 & 9.56 \\
\hline (Abbas et al., 2013) & 3.2 & 3.33 & 4.21 & 11.5 \\
\hline (Raziq et al., 2008) & 2.63 & 4.01 & 3.11 & 10.45 \\
\hline (Konuspayeva et al., 2009) & 5.94 & 3.03 & 3.12 & 12.39 \\
\hline
\end{tabular}

\section{a) Casein in Camel Milk}

Camel milk is a tremendous source of proteins among which casein is a major source $(1.5-2.75 \%)$ that contributes 50 to $85 \%$ of the total milk proteins (Khaskheli et al., 2005).Like human milk, camel milk proportionally contains $65 \% \beta-\mathrm{CN}$ and $21 \% \alpha_{\mathrm{S}_{1}}-\mathrm{CN}$, while in the bovine milk $38 \%$ is $\alpha_{\mathrm{S}_{1}}-\mathrm{CN}$ and $36 \%$ is $\beta-\mathrm{CN}$. Camel milk has ability to be easily digested and shows less allergic reactions in children due to the absence of beta-lactoglobulin. Variation in casein proportion has been observed with respect to kcasein in camel $(3.46 \%)$ and bovine $(13 \%)$ milk. It has been approved from other scientists that k$\mathrm{CN}$ don't show its effect as it is in low concentration because it does not give any bands when checked by using electrophoresis.

It has been analyzed that in camel milk $\alpha$-lactalbumin has more potential as an antioxidant compared to bovine $\alpha$-lactalbumin. The reason behind this fact is that camel milk $\alpha$-lactalbumin has such amino acids residues that show more antioxidant properties (Salami et al., 2009). Keppa ( $\kappa$ )-casein in camel milk has 162 amino acids, $22.4 \mathrm{Kda}$ molecular weight and isoelectric point (IP) is $4 \cdot 11$. These proteins have five different sites of sialylated glycosylation in five different position of threonine at 105, 109, 149, 152 and 153. The cleavage site of chymosin is Phe 97- Ile 98. Camel milk casein cannot be easily separated from whey protein even precipitation at $4.5 \mathrm{pH}$ due to difference in isoelectric point. The structure of camel milk casein micelles resembles to the ruminant casein micelles which is of spherical orientation however, difference is in diameter that is $380 \mathrm{~nm}$ of camel, $150 \mathrm{~nm}$ of bovine, $260 \mathrm{~nm}$ of caprine and $180 \mathrm{~nm}$ of bovine milk.

Another study on the size distribution of casein has illuminated size variations as $0 \cdot 4-0 \cdot 5 \mu \mathrm{m}$ in camel milk and $0 \cdot 13-0 \cdot 16 \mu \mathrm{m}$ in cow milk. However, the average diameter is inversely associated to the concentration of $\mathrm{CaPO}_{4}$ and $\kappa$-caseinwhich effects functionality of camel milk in the structure stability or formation of gel. If the surface area of casein micelles is enhanced it will result in strengthening of gel and firming the texture of curd as compared to poor aggregated gel in case of large size micelle.

Camel milk casein possesses tremendous nutritional properties as many studies on casein micelles showed that casein has unique attributes as compared to other dairy milk casein. Minerals in camel 
milk micelle phase are Phosphorous $(\mathrm{P})$, Magnesium $(\mathrm{Mg})$ and Calcium $(\mathrm{Ca})$ that also take part in casein micelle formation while sodium and potassium are in free form. In case of camel milk $\mathrm{Mg}$ and $\mathrm{P}$ both equally participated in casein formation while in case of cow milk $2 / 5$ for the $\mathrm{Mg}$ and $1 / 3$ for the $\mathrm{P}$ are involved. It results in more amounts of $\mathrm{Mg}$ and $\mathrm{P}$ in camel milk casein micelles that cause more salinity and decreases $\mathrm{pH}$ and increased coagulation that ultimately caused poor gel stability.

\section{$>$ Whey Protein}

The main components of whey protein are;

- $\alpha$-lactalbumin $(\alpha$-LA)

- $\beta$-lactoglobulin ( $\beta$-LG)

- Serum Albumin (SA)

- LactoFerrin (LF)

- Immunoglobulins (Ig)

These components vary in different species on the basis of their quantity. The most abundant whey proteins are $\alpha-\mathrm{LA}$ and $\beta-\mathrm{LG}(70-80 \%)$ in cow's milk but in camel milkthere is no $\beta$-LG and contains a large quantity of serum albumin as compared to $\alpha$-LA. The major components are IgG and Gly CAM1 while peptidoglycan recognition protein (PGRP-S) and lactoferrin (LF) are in minute quantities. Camel milk colostrum whey contains large amounts of immunoglobulins and serum albumin. On very first day of colostrum milk contains $12.5 \mathrm{~g} / \mathrm{L}$ of Ca while on eighth day it is $9 \cdot 2 \mathrm{~g} / \mathrm{L}$. as compared to colostrum of bovine whey which contains large amount of $\beta$-LG. Camel milk casein is in two forms " $\alpha \mathrm{S} 1$-casein" and " $\alpha \mathrm{S} 2$-casein" among which there are two isoforms of $\alpha \mathrm{S} 1$ i.e. A and B. A form contains 207 amino acid residues and molecular weight (MW) is $24.668 \mathrm{kDa}$ and B form contains 215 amino acid residues and MW is $24.755 \mathrm{kDa}$. $\alpha \mathrm{S} 2$-casein contain 178 amino acid residues with MW of $21.993 \mathrm{kDa}(E l-A g a m y, 2006)$. In bovine milk essential amino acids are methionine, ileuline, leucine and phenylalanine and all non-essential amino acids other than arginine are in higher amount in $\alpha$ casein as compared to $\alpha$-casein of camel milk (Salmen et al., 2012). $\beta$-casein of camel milk contains 217 amino acid residues and a MW of $24,900 \mathrm{kDa}$ and it contains relatively lower quantity of valine, phenylalanine, histidine, glycine and serine (Salmenet al., 2012).

\section{b) Bioactive Native Proteins and Its Derived Components in Camel Milk}

Unlike other milk proteins, camel milk contains relatively higher amount of bioactive immune proteins having therapeutic and medical properties. Some of the important bioactive protein components have been reviewed as detailed below:

\subsection{Immunoglobulins}

Immunoglobulins are protective proteins produced by the plasma and lymphocytes plays significant role in the immune system of the host. They attach with foreign materials like bacteria viruses' antigens and help to destroy them. There are five classes of Immunoglobulins including immunoglobulin $\mathrm{G}(\operatorname{IgG})$, and immunoglobulin $\mathrm{M}(\operatorname{IgM})$, immunoglobulin $\mathrm{D}(\mathrm{IgD})$, immunoglobulin A ( $\operatorname{IgA}$ ), and immunoglobulin E (IgE). Numerous factors affect the concentration of immunoglobulins in milk like species, stage of lactation and health status of animal. The camel milk immunoglobulins possess preposterous potential against infectious diseases. The very small size of camel milk $\left(1 / 10^{\text {th }}\right.$ human antibodies) immunoglobulins makes them easier to pass the blood-brain barrier and digested readily from gut to the circulation (Alhaider and Abdel Gader, 2016). Furthermore, the concentration of $\mathrm{IgG}$ is $1.64 \mathrm{mg} / \mathrm{mL}$ in camel milk that is highest as compared to $0.55,0.63,0.67,0.70$ and 0.86 $\mathrm{mg} / \mathrm{mL}$ in sheep, buffalo, cow, goat and human milk.

\subsection{Lactoferrin}

Lactoferrin, a glycoprotein, that is also recognized as lacto-transferrin has the ability to bind 2 metal ions $\left(\mathrm{Fe}^{3+}\right.$ preferably) at the binding sites that are closely related in structure. It belongs to a class of transferrin; most part of this protein is required to transport or store the iron and described to function as iron scavenger in body secretions. Human milk was found to contain highest level of lactoferrini.e. $1.7 \mathrm{mg} / \mathrm{mL}$ while donkey milk contains lowest level i.e. $0.07 \mathrm{mg} / \mathrm{mL}$. Camel milk contains $0.22 \mathrm{mg} / \mathrm{mL}$ lactoferrin contents significantly higher than sheep, goat, cow and buffalo milk (Abbas et al., 2013). 
Another research revealed that after parturition on second day the colostrum camel milk had higher lactoferrin content i.e. $5.1 \mathrm{mg} / \mathrm{mL}$ as compared to colostrum milk of cow i.e. about $0.5 \mathrm{mg}$. $\mathrm{mL}^{-1}$. This level dropped to $0.34 \mathrm{mg} / \mathrm{mL}$ in camel milk after one month of parturition and $0.06 \mathrm{mg} / \mathrm{mL}$ in cow milk. Among all the protective proteins in camel milk lactoferrin acts as a multi-functional protein including the strong pathological effects.

\subsection{Lactoperoxidase}

The occurrence oflacto-peroxidase is reported in milk, saliva and tears. Camel milk lactoperoxidase possesses anti-bacterial properties against gram-negative bacteria and aids host non-immune defense system. It is closely related to the human thyroid peroxidase $(71 \%)$ and assists in iodination and coupling in thyroid hormone formation. The resistance of camel lacto-peroxidase against the acids and proteins digestion is well reported. Camel milk lactoperoxidase is a protein monomer showing about $79.2 \%$ similarity with human eosinophil peroxidase and $79.3 \%$ similarity to human myeloperoxidase in sequence. Both peroxidases are dimeric proteins. Extraction and purification of camel and bovine milk lactoperoxidaseshave been done which show approximately 78 and $88 \mathrm{kDa}$ molecular weights, respectively (Abbas et al., 2013; Gul et al., 2015b)

\subsection{Lysozyme}

Protective protein lysozyme was found highest in camel milk followed by human and cow milk. Lysozyme has antimicrobial properties especially against gram-positive bacteria. Lysozyme breaks $\beta$ (1-4) glycosidic linkage between $\mathrm{N}$-acetyl-D-glucosamine and $\mathrm{N}$-acetylmuramic acid in peptidoglycan which forms microbial cell walls. Immunological studies on lysozyme indicated no antigenic similarity between camel and bovine milk lysozyme i.e. they have alike structures (Gul et al., 2015b).

\subsection{Peptidoglycan Recognition Protein (Pgrp)}

Camel milk contains maximum amount of peptidoglycan recognition protein that shows an excellent effect for controlling the breast cancer by strengthening patient's immune system. It owns tremendous antimicrobial properties and showed significant effects against the food borne pathogens in different studies (Gizachew et al., 2014b; Gul et al., 2015b)

\subsection{Heat Stability of Protective Proteins}

Research has been done to investigate effect of heat treatment on protective proteins such as immunoglobulins ( $\mathrm{IgG}$ ), lactoferrin and lysozyme present in camel, buffalo and cow milks after skimming. Milk from these species was heated at $65,75,85$ and $100^{\circ} \mathrm{C}$ for 30 mins and it was found that heating at $65^{\circ} \mathrm{C}$ for $30 \mathrm{mins}$ did not affected the lactoferrins and lysozymes significantly however, a significant reduction in immunoglobulin's function was observed. Immunoglobulins of both cow and buffalo milks lost their activity entirely after heating at $75{ }^{\circ} \mathrm{C}$ for 30 mins however, camel milk immunoglobulins showed $68.7 \%$ reduction in activity. Lactoferrin in all of these three types of milk lost its activity after heating at $85^{\circ} \mathrm{C}$ for 30 mins, however, in case of lysozyme 56,74 and $81.7 \%$ loss in activity was observed for camel, cow and buffalo, respectively. In general, protective proteins of camel milk are found to be more stable to heat as compared to cow and buffalo milk.

\subsection{Camel Milk Fat}

In dromedary camels, milk fat levels vary from $1.2 \%$ to $4.5 \%$ depending upon the nutritional status, lactation stage, breed type and the season. The waxy texture of camel milk as compared to other species is due to presence of higher amount of unsaturated fatty acids (Zhang et al., 2005). The fat contents were found to decrease from 4.3 to $1.1 \%$ in thirsty camel (Konuspayeva et al., 2009). Lower amount of short chain fatty acids and carotene are found in camel milk as compared to the bovine (Stahl et al., 2006). The white color of camel milk is because of lesser content of carotene. Unlike, long chain fatty acids in bovine milk are in higher amount than camel milk. Similarly, unsaturated fatty acids particularly essential fatty acids were found to be highest in camel milk i.e. $43 \%$ (Haddadin et al., 2008). Camel milk fat contains lower amount of saturated fatty acids i.e. $67.7 \%$ as compared to cow milk i.e.69.9\% (Konuspayeva et al., 2008). Milk from camel exhibited 50-65\% saturated and 35$50 \%$ unsaturated fatty acids. 


\subsection{Carbohydrates in Camel Milk}

Lactose is the main fraction of carbohydrates in camel milk. The one humped camel milk contains 2.3 to $5.82 \%$ lactose (Konuspayeva et al., 2009). During grazing in dessert, camel usually consumed halophilic, acacia, artiplex, and salosa plants to meet their substantial requirements. Consequently, camel milk is often explained as salty sweet. This might be an important aspect for large variations in lactose contents (Abbas et al., 2013).Lactose contents showed no change in hydrated or dehydrated conditions over a time. However, in case of one humped type camel, some of them showed slight change in lactose contents over a period on lactation (Kula and Tegegne, 2016).

\subsection{Vitamin and minerals in camel milk}

Camel milk contains higher amount $\mathrm{Fe}, \mathrm{Cu}, \mathrm{Zn}$ and $\mathrm{Mn}$ whilst, the concentration of other major minerals like $\mathrm{Na}, \mathrm{K}, \mathrm{Ca}, \mathrm{P}$, and $\mathrm{Mg}$, in camel milk is similar to cow milk. Total ash in dromedary camel milk ranges in between 0.60-0.90\% (Konuspayeva et al., 2009). However, variation in ash contents is attributed to rearing practices, other factors stated elsewhere and obviously the data analytical procedures (Haddadin et al., 2008). Abbas et al. (2013) has reported the values of several milk mineral elements in their research that are important from the source point of view. The ratio of Ca to $\mathrm{P}$ is found to be 1:5 in camel milk as compared to 2:1 and 1:29 for human and cow milk, respectively. This ratio has importance as the cow milk-based formula used for infant feeding contains high phosphate; which can cause hyperphosphatemia and low calcium in serum (Kumar et al., 2015). Feed like artiplx and acacia contributes higher quantity of salts in camel's milk therefore, the milk is considered as a good chloride source. The studies have established that $\mathrm{Fe}$ is involved in different biological processes, including DNA synthesis and transportation as well as its storage of oxygen (Khaskheli et al., 2005).

The fat (A, D and E) and water (C and B) soluble vitamins are present in higher quantities in milk from camel (Stahl et al., 2006; Haddadin et al., 2008). The concentration of niacin (B3) has also been reported as higher in camel milk. Camel milk comprises large amount $(34.16 \mathrm{mg} / \mathrm{L})$ of vitamin $\mathrm{C}$ i.e. 3-5 times more as compared to the cow milk. Thus, camel milk is an efficient alternate source of vitamin $\mathrm{C}$ for the desert areas inhabitants where vegetables and fruits are hard to reach. The higher concentration of ascorbic acid in camel milk lowers the $\mathrm{pH}$ and provides more stability for longer time without phase separation. Despite of shelf stability, vitamin C exerts a strong anti-oxidant potential (Mal et al., 2006). Ascorbic acid and vital electrolytes e.g. Ca and Fe are required for duodenal acid for the absorption of calcium in osteoporosis cases. Camel milk can satisfy this as it rapidly passes the stomach with constant secretion of acid and with ascorbic acid, increasing the amount of $\mathrm{Ca}$ absorption and depositing in the bones. USDA states that quarter liter of milk from dromedary camel provides $5.25 \%$ of vitamin A, $8.25 \%$ of vitamin B2, $10.5 \%$ of vitamin C, $15.5 \%$ of vitamins B1, B6 and B12 of the recommended daily allowance (RDA) to a normal adult. Comparing cow milk, the same amount of bovine milk provides $9 \%$ of vitamin A, $36 \%$ of vitamin B2, 3.5\% of vitamin C, $11.5 \%$ of vitamin B6, and $43.5 \%$ of vitamins B1 and B12 of the RDA (USDA, 2009).

\subsection{Nutritional Importance of Camel Milk}

The milk obtained from camel is structurally and compositionally different from cow along with the presence of all the essential nutrients found in cow milk. Camel milk contains 3-5 times higher vitamin $\mathrm{C}$ as compared to cow milk and $1 / 5$ of human milk. Nutritionally, $1 \mathrm{~kg}$ of camel milk provides daily sufficient nutrients for human requirements while fulfill the minerals recommended daily allowance (RDA) of the individual. It has potential health benefits particularly in diabetes and liver diseases. Camel milk is devoid of $\beta$-lactoglobulin that makes it healthy for milk allergic persons in comparison to cow milk. Camel milk possesses low saturated milk fat and abundantly polyunsaturated fatty acids. It is also a rich source of immune proteins and these are reported more compatible to human milk protective proteins.

Camel milk contains huge amount of vitamins A, B, C, D, E and Niacin (B3). It is reported that camel milk acquires three to five times vitamin $\mathrm{C}$ as compared to cow milk. Furthermore, $250 \mathrm{~mL}$ of camel milk provides $10.6 \%$ vitamin C, $5.26 \%$ vitamin A, $8.26 \%$ riboflavin (B2), $15.5 \%$ cobalamin, pyridoxine and thiamin of their RDA in comparison to cow milk (USDA, 2009). The higher amount of ascorbic acid in camel milk provides more shelf stability without coagulation for longer periods. The huge concentration of ascorbic acid in camel milk not only meets the nutritional requirements but also provides medicinal benefits with respect to anti-oxidant potential. 


\subsection{Therapeutic/Medicinal Properties of Camel Milk}

The health benefits of camel milk are due to naturally present bioactive components that have been reported by several researchers (Agrawal et al., 2007). The evidence of camel milk's therapeutic potential against many viral and infectious diseases has been identified (Asresie and Yusuf, 2014). It is established that camel consumed many dessert plants during grazing having medicinal properties against many diseases. The milk has been used by number of people for curing several ailments e.g. jaundice, malaria, constipation, clearing the stomach, post-partum care of women, detoxifying snake venom and alleviating flatulence. It is well recognized that camel milk is globally used for curing dropsy, tuberculosis, asthma and leishmaniasis or kala-azar as concluded by Asresie and Yusuf (2014) during studies on consumption and therapeutic products of camel milk in East region Somalia.

The milk contains many protective proteins which have bactericidal, fungicidal and viricidal properties that strengthen the host's immune system and prevents microbial growth in gut, participates in primary immune system based on targeting of structures common to invade pathogens. Peptides and proteins have shown biological activities on host's immune system by targeting and invading pathogens. These exertbeneficial effect on many bioprocesses as digestion, absorption, growth and immunity. Moreover, camel milk acquires more shelf life and can be stored at room temperature for longer periods than milk from other animals (Yassin et al., 2015). The consumption of camel milk has been increased worldwide due to several health benefits. Camel milk possesses tremendous therapeutic properties against different lifestyle related disorders. Hence, potential health benefits of camel as strong anti-oxidant, bactericidal, veridical, fungicidal and anti-carcinogenic properties have been endorsed by several investigations (Sharma and Singh, 2014)

\subsection{Anti-Diabetic Effect}

Diabetes mellitus is a metabolic disorder in which blood glucose level is increased as compared to the normal concentration resulting in low insulin production and increased insulin resistance (Abdel Gader and Alhaider, 2016). In type-1 diabetes, the beta cells of pancreas are destroyed and unable to produce required amount of insulin for proper body functioning and results in higher level of blood and urine sugar. The therapeutic protein in camel milk is suitable in repairing damaged tissue of the beta cells and helps to cure metabolic disorder (Gul et al., 2015b).

In 2013, comparative studies were carried out in India on the diabetic patient to check the effect of camel milk. The patients treated with camel milk supplementation exhibited significant reduction in blood glucose and reduced $\mathrm{HbA1C}$ level as compared to conventionally treated patients. It was observed that camel milk has ability to repair damaged beta cells and possess regulatory and immune modulatory effect on the cells (Agrawal et al., 2009). Lately, Gizachew et al. (2014b) studied nutritional and medicinal properties of camel milk and concluded that camel milk contains $150 \mathrm{U} / \mathrm{mL}$ insulin concentrations which is highest amount of insulin as compared to other milk species. The unique property of camel milk insulin is its resistance to degradation even in the acidic environment of stomach unlike human, cow and goat milk. The insulin can easily pass through upper gastrointestinal tract without proteolysis. It is encapsulated in fat globules in the form of nanoparticles which make its absorption easier and facilitate passing to the blood stream. This equity ranked camel milk as therapeutic and medical milk for alleviating metabolic syndrome like hyperglycemia, hyperlipidemia and insulin resistance condition.

According to Bikaner research institute (2005), regular consumption of camel milk not only showed reduction in blood glucose but also reduced the dose of medicine for the diabetic patients in type 1 diabetes while maintaining blood glucose level for a longer time. This research also elucidated that the concentration of insulin is higher as compared to other animal milk sources. The concentration of insulin in camel milk was found to be highest. Furthermore, it is proved that camel milk is safe, efficacious for the reduction of blood glucose level and maintaining long term glycemic control in diabetic patients (Agrawal et al., 2009).

Biochemical studies resulted the affirmation of bioactive elements contained by camel milk e.g. lactoferrin, immunoglobulins and insulin like protein make the camel milk super food for the diabetic patients. In parallel, epidemiological studies were carried out in different camel milk consuming communities and declared less or zero diabetic patients. Additionally, an experimental study was performed for the evaluation of antidiabetic potential of camel milk. Two groups were studied for 
comparative studies, group I patients received the usual care, exercise and medicine while, group II received camel milk along with the usual care and medicine. The results showed significant decrease in blood glucose, insulin requirement and less medicine for the camel milk supplemented group. For the group receiving camel milk supplementation, the insulin requirement reduced to zero, at the end of the study. There was non-significant change in plasma insulin and anti-insulin antibodies in both groups. It may be proven that the consumption of camel milk aids in lowering blood glucose and maintains long term glycemic controls in diabetic patients.

\subsection{Fastidious Pathological Effect of Camel Milk}

Camel milk possesses bactericidal effect against gram-positive and gram-negative bacteria (Benkerroum et al., 2004). Camel milk acquires antimicrobial potential due to bioactive components like lactoferrin, hydrogen peroxide, immunoglobulins, lysozyme and lacto-peroxidase. Camel milk lactoferrin constrains Salmonella typhimurium growth by binding iron and making it unavailable for growth.

Another study exhibited that camel milk has antimicrobial activity because of its indigenous enzymes, antibacterial and antiviral characteristics. Colostral camel milk contains lactoferrin (an iron binding protein) which acts as iron scavenger and depletes the milk from free iron and ultimately slows down the growth of microbes. The iron-binding glycoprotein lactoferrin is found in various natural mammals' fluids e.g. milk, serum and blood etc. The antibacterial potential of lactoferrin has been examined and iron-saturated glycoprotein present in camel milk from the start to the end of the lactation period plays antimicrobial role in human gut particularly. The action aids in preventing attack of microorganisms in newly born because of undeveloped immune system. In addition to antibacterial and antifungal potential, it also exhibits antiviral activity against rotavirus, herpes viruses, HIV and respiratory syncytial virus.

Camel milk is an excellent alternative for those people who are allergic to cow milk because it does not contain harmful pathogens and $\beta$-lactoglobulin. In order to determine its antimicrobial effect, the prevalence of Listeria monocytogenes in camel milk was evaluated. Camel milk is the best source of milk for human with numerous therapeutic properties absent in the milk of rest of milch animals.

In another study, milk from different animals was collected to study the presence of Listeria spp. showing anti-listerial behavior of the camel milk. Milk lysozyme inhibits the growth of bacteria effectively during storage of camel milk however; immunoglobulins possess tremendous advantage over conventional antibodies (Wernery, 2006). Furthermore, lysozyme improves the anti-bacterial action of lactoferrin.

Camel milk contains enzymes, protective proteins and reduced size immunoglobulins as compared to the other ruminant's milk with powerful antimicrobial effect. The concentration of lactoferrin and lysozymes is higher in camel milk as compared to the bovine milk (Konuspayeva et al., 2009). Other studies have also shown the antimicrobial and bactericidal effect of camel milk lactoferrin.

Experimental minimum inhibitory concentration (MIC) values have shown the wide range of camel lactoferrin activity as it has been proved by several researches who declared that camel lactoferrin possesses inhibitory activity against both gram-negative and gram-positive bacteria. Camel milk pathological behavior has also been explained by many researchers against $E$. coli and $L$. monocytogenes. Camel colostrum is reported to show bactericidal effect against E. coli and bacteriostatic effect against $L$. monocytogenes. Raw camel milk possesses more antimicrobial effect as compared to boiled camel milk because after heating the indigenous inhibitory system of camel milk is destroyed (Benkerroum et al., 2004).

The antimicrobial enzymes like lysozymes are heat sensitive and inactivated at $80^{\circ} \mathrm{C}$ for $45 \mathrm{~s}$ or at $76^{\circ} \mathrm{C}$ for $1 \mathrm{~min}$. The pathological studies of protective proteins against gram-positive, gram- negative and rotavirus are well reported. In another study, camel milk protective proteins like lactoferrin, lactoperoxidase, lysozyme, immunoglobulin G and secretory immunoglobulin A are extracted from the milk and could be effective against the Escherichia coli, Lactococcuslactis subsp. cremoris, Salmonella typhimurium, Staphylococcus aureus, and rotavirus. Studies revealed, that LP from camel milk was found to be bacteriostatic against the gram-negative and gram- positive strains however, immunoglobulins showed little effect against bacteria but high effectiveness against rotavirus.Inspite of several other medicinal benefits, camel milk has been proved significantly to retain medicinal effects 
against Tuberculosis and on MDR (multiple drug resistance) patients with tuberculosis (Mal et al., 2006).

The latest research showed bactericidal activity of camel milk casein. Caseins fragments were hydrolyzed by pepsin and pancreatin successively with molecular weight below $1 \mathrm{kDa}$. The inhibitory property of proteolytic enzymes hydrolyzed casein was more effective, as compared to the native caseins of camel milk. Camel milk has also been reported as pathologically effective against pathogenicity induced by E. coli and S. aureus(Mal et al., 2006). Additionally, dromedary milk owns antagonistic response with antibiotics that might use for reduction of antibiotics and scale down activity of bacteria (Yassin et al., 2015).

\subsection{Prevention from Crohn'S Disease}

In Crohn's disease the inflammation of bowel occur which effects the digestive tract and gut results in abdominal cramping. This abnormality condition occurred by Mycobacterium avium subspecies that leads to Crohn's diseas. Peptidoglycan recognition protein (PGRP) has strong bactericidal effects of camel milk $(\mathrm{CM})$ that provides significantly positive results on healing process. The individuals suffering from infection aliments are being well recovered by the regular consumption of raw camel milk. Researchers reported that camel milk has shown good effect for treating Crohn's disease (Shabo and Yagil, 2005). Along with powerful pathological and medicinal effect, camel milk consumption aids in strengthening the immune's host system due to powerful immunoglobulins and PGRP present in camel milk (Yadav et al., 2015).

\subsection{Anti-Allergic Properties of Camel Milk}

The $\beta$-lactoglobulin is a whey protein which is responsible for the allergic action in human. Sometimes $\beta$-caseins cause hypersensitivity in individuals. Camel milk lacks in allergic actions due to absence of $\beta$-lactoglobulin and different structure $\beta$ - caseins as compared to bovine milk. Camel milk supplementation improves severe allergic problems rapidly in infants (Gizachew et al., 2014b).

The difference in immunological properties of cow and camel milk proteins developed a criterion for clinical usage of camel milk. Consequently, the milk may be proposed to new protein source for the newborn which are allergic to bovine milk. After ingestion of milk from cow, buffalo, goat and mare some consumer suffers severe allergic problems due to complex proteins consequently the camel milk is considered as the best alternative to bovine milk.

\subsection{Miracle Milk for Lactose Intolerance}

Individuals who are intolerant to lactose can consume camel milk without any deleterious symptoms. An explanation for this phenomenon has not yet been found. It was suggested that the lactose in camel milk is readily metabolized. Although, it possesses higher amount of lactose as compared to human milk but lactose present in camel milk is readily digested by human lactase with no signs of lactose intolerance.

\subsection{Anti-Diarrheal Properties of Camel Milk}

Globally, diarrhea kills the 760,000 children under and above five years every year due to unclean water.Camel milk acquires plenty of protective proteins like lysozymes lacto-peroxidase, lactoferrin, PGRP and NAGase which provide significant bactericidal, veridical and anti-diarrheal effects by strengthening the host body immune system. Rotavirus is the predominant root cause of diarrhea in children under 5 years. Camel milk anti-bodies work efficiently against rotavirus in diarrheal children resultantly improving the immune system due to rich anti-rotavirus antibodies and protective proteins of camel milk.

\subsection{Therapeutic Potential of Camel Milk on Cancer, Tumor and Ulcer}

In vitro studies showed that camel milk LF is capable of inhibiting propagated cancer cells by repairing the damaged DNA reported that the Fe binding protein LF reduced cancer cells growth by $56 \%$. Earlier, camel milk showed a positive effect on human cancer cells (Alhaider and Abdel Gader, 2016). Recent in vitro findings, provided the evidence of dromedary milk for growth inhibitory action against malignant cancer cells in human glioma cells lines, hepatocellular carcinoma cell lines, lungs carcinoma, colon and blood cancer. The investigation also explained that anti-cancer action of camel milk LF could be both as direct cell cytotoxicity and anti-angiogenic action (cutting blood supply to 
tumor cell). The camel milk active antibodies bind the target sites more efficiently due to their small size as compared to human antibodies without damaging the healthy tissues and eliminate the cancer cells.

Camel milk is a rich source of anti-cancer equities because of strong pathological anti-oxidative potential which aids in mitigating liver viral infection due to beneficial nutrients (Kula and Tegegne, 2016). This milk possesses a large amount of vitamin C, A, B2 and $\mathrm{E}$ and huge amount of $\mathrm{Zn}$ and $\mathrm{Mg}$ which help in ulcer treatments. These electrolytes not only assist in reduction of oxidative stress that is produced by harmful substances but also aids in the absorption and metabolism of vitamins. Furthermore, Mg helps in the synthesis of glutathione which hinders cellular injury induced by free radicals, heavy metals and peroxides. Previously, it has been found that $\mathrm{Mg}$ positively increases the antioxidant defense mechanism. The defensive response of zinc in cell toxicity and apoptosis caused by oxidative stress has been well documented (Kula and Tegegne, 2016). Additionally, dromedary milk may produce the $\mathrm{NO}_{2}$ which promptmucous formation that hinders endothelial cells and raises blood flow to gastric mucous membrane.

\subsection{Camel Milk and Aging}

The researchers revealed potential anti-aging benefits of camel milk after regular consumption in various experiments. After digestion, peptides produced acting as natural antioxidants and angiotension converting enzyme (ACE) -inhibitors. It has been stated that camel milk contains 3 to 5 times more vitamin $\mathrm{C}$,that helps to protect collagen. Ascorbic acid antioxidants play an important role in repairing and protecting of tissues. The water-soluble vitamin $\mathrm{C}$ strengthens the immune system due to antioxidant potential. Natural standard research reported the role of vitamin $\mathrm{C}$ for the healthy growth of blood cells and vessels due to collagen production. Antioxidant potential of camel milk retards production rate of free-radical activity that results in the skin dryness and wrinkles.

Furthermore, $\alpha$-hydroxyl acids due to vitamin $\mathrm{C}$ in camel milk demonstrates anti-aging effects by removing outer dead cells of skin (epidermis) which assists in glowing smoothness of skin. Furthermore, alpha-hydroxyl supports in producing new skin cells and helps to eradicate wrinkles and spots of skin. Liposome present in camel milk is being used potentially as important ingredient in anti-aging cosmetic products.

\subsection{Camel Milk Treatment in Hepatitis}

Hepatic malfunctions are quite prevalent around the globe, arising from pathological invasion of viruses or chemical exposure. Experimental research exhibited potential health benefits of camel milk against hepatitis $\mathrm{B}$ and $\mathrm{C}$. The unique fat molecules in dromedary milk provide relive to the liver and helps in chronic liver ailment. The ascorbic acid concentration is higher in camel milk which enhances the liver functionality in chronic hepatic disorder (Gul et al., 2015b).

Successive investigation proved that camel LF remarkably effects hepatitis $C$ virus genotype and also provides the counter effects for virus entry into cells (Alhaider and Abdel Gader, 2016). Furthermore, camel LF $(0.135 \mathrm{mg} / \mathrm{mL})$ owns more anti-viral capacity as compared to bovine and human lactoferrin. Camel milk possesses significant amount of calcium, magnesium, zinc, iron, potassium and lactoferrin which have chelating effects. Alongside, bone problems, joints pain and arthritis can be treated by regular consumption of camel milk.

\section{CONCLUSION}

Camel is nature's incredible creature for nomads and pastoralists in different parts of the world due to its adaptability in harsh conditions. Camel milk is nutritionally balanced in all aspects and is considered as a nature's pharmacy for the masses owing to its medicinal and therapeutic characteristics. The camel maintains its milking potential in the stridulous climate, where other livestock survival is questioned. Compositionally, camel milk contains three times more vitamin $\mathrm{C}$ as compared to bovine milk, which acts as antioxidant, also meets the nutritional requirements of peoples in hot and arid environments. Camel milk owns remarkable anti-diabetic potential and contains $52 \mathrm{U}$ insulin/L. Globallymost of the camel milk is utilized in fresh form by the camel rearing people to fulfill their needs. The trend of human population is increasing so rapidly that it would be increased $35 \%$ in 2050. This increasing trend in human population is not only paying stress on already available food resources but also becoming threat to food security by each passing day. In this 
situation, new food resources need to be explored and camel milk is one of the potential and valuable tools to combat this situation. In this respect, value-addition, processing and proper marketing of camel milk and milk products is necessary, enabling us to address food insecurity by meeting population needs.

\section{REFERENCES}

[1] Abbas, S., H. Ashraf, A. Nazir and L. Sarfraz. 2013. Physico-chemical analysis and composition of camel milk. International Research. 2:85-98.

[2] Abdel Gader, A.G.M. and A.A. Alhaider. 2016. The unique medicinal properties of camel products: A review of the scientific evidence. Journal of Taibah University Medical Sciences. 11:98-103.

[3] Agrawal, R., S. Budania, P. Sharma, R. Gupta, D. Kochar, R. Panwar and M. Sahani. 2007. Zero prevalence of diabetes in camel milk consuming Raica community of north-west Rajasthan, India. Diabetes Research and Clinical Practice. 76:290-296.

[4] Agrawal, R.P., R. Dogra, N. Mohta and R. Tiwari. 2009. Beneficial effect of camel milk in diabetic nephropathy. Acta Bio Medica Atenei Parmensis. 80:131-134.

[5] Ahmed, S.K., R. Haroun and M.O. Eisa. 2010. Banana frozen yoghurt from camel milk. Pakistan Journal of Nutrition. 9:955-956.

[6] Al-Juboori, A., M. Mohammed, J. Rashid, J. Kurian and S. El Refaey. 2013. Nutritional and medicinal value of camel (Camelus dromedarius) milk. WIT Transactions on Ecology and the Environment. 170:221-232.

[7] Al Kanhal, H.A. 2010. Compositional, technological and nutritional aspects of dromedary camel milk. International dairy journal. 20:811-821.

[8] Alhaider, A.A. and A.G.M. Abdel Gader. 2016. The unique medicinal properties of camel products: A review of the scientific evidence. Journal of Taibah University Medical Sciences. 11:98-103.

[9] Ali, M.Z., A.S. Qureshi, M. Usman, R. Kausar and M.K. Ateeq. 2017. Comparative Effect of Camel Milk and Black Seed Oil in Induced Diabetic Female Albino Rats. Pakistan Veterinary Journal. 37:293-298.

[10] Asresie, A. and M. Yusuf. 2014. Traditional Consumption, Therapeutic Value and Its Derived Dairy Products of Dromedary Camel (Camelus Dromedaries) Milk in Somali Regional State, Eastern Ethiopia: A Review. Global Journal of Animal Scientific Research. 3:240-246.

[11] Benkerroum, N., M. Mekkaoui, N. Bennani and K. Hidane. 2004. Antimicrobial activity of camel's milk against pathogenic strains of Escherichia coli and Listeria monocytogenes. International Journal of Dairy Technology. 57:39-43.

[12] Conesa, C., L. Sánchez, C. Rota, M.-D. Pérez, M. Calvo, S. Farnaud and R.W. Evans. 2008. Isolation of lactoferrin from milk of different species: calorimetric and antimicrobial studies. Comparative Biochemistry and Physiology Part B: Biochemistry and Molecular Biology. 150:131-139.

[13] El-Agamy, E. 2006. Camel milk. Handbook of milk of non-bovine mammals.297-344.

[14] Faraz, A., M.I. Mustafa, M. Lateef, M. Yaqoob and M. Younas. 2013. Production potential of camel and its prospects in Pakistan. Punjab Univ. J. Zool. 28:89-95.

[15] Faye, B. 2016. The camel, new challenges for a sustainable development. Springer.

[16] Faye, B. and P. Bonnet. Camel sciences and economy in the world: current situation and perspectives. Proc. 3rd ISOCARD conference. Keynote presentations. 29th January-1st February, 2012. 2-15.

[17] Faye, B. and G. Konuspayeva. 2012. The sustainability challenge to the dairy sector-The growing importance of non-cattle milk production worldwide. International dairy journal. 24:50-56.

[18] Gader, A.G.M.A. and A.A. Alhaider. 2016. The unique medicinal properties of camel products: A review of the scientific evidence. Journal of Taibah University Medical Sciences. 11:98-103.

[19] Gizachew, A., J. Teha, T. Birhanu and E. Nekemte. 2014a. Review on medicinal and nutritional values of camel milk. Nature and Science. 12:35-41.

[20] Gizachew, A., J. Teha, T. Birhanu and E. Nekemte. 2014b. Review on medicinal and nutritional values of camel milk. Nature and Science. 12:35-40.

[21] Gul, W., N. Farooq, D. Anees, U. Khan and F. Rehan. 2015a. Camel milk: a boon to mankind. IJRSB. 3:23-29.

[22] Gul, W., N. Farooq, D. Anees, U. Khan and F. Rehan. 2015b. Camel Milk: A Boon to Mankind. International Journal of Research Studies in Biosciences (IJRSB). 29:23-29.

[23] Habib, H.M., W.H. Ibrahim, R. Schneider-Stock and H.M. Hassan. 2013. Camel milk lactoferrin reduces the proliferation of colorectal cancer cells and exerts antioxidant and DNA damage inhibitory activities. Food Chemistry. 141:148-152. 
[24] Haddadin, M.S., S.I. Gammoh and R.K. Robinson. 2008. Seasonal variations in the chemical composition of camel milk in Jordan. Journal of Dairy Research. 75:8-12.

[25] Kalla, K., V. Manthani and S. Keerthi. 2017. Camel Milk An White Gold Of Dessert-A Review. International Archive of Applied Sciences and Technology. 8:74-83.

[26] Khan, R., M.I. Shahzad and M.N. Iqbal. 2016. Role of Camel in Pastoral Mode of Life and Future Use of rCGH as a Therapeutic Agent in Milk and Meat Production. PSM Veterinary Research. 1:32-39.

[27] Khaskheli, M., M. Arain, S. Chaudhry, A. Soomro and T. Qureshi. 2005. Physico-chemical quality of camel milk. Journal of Agriculture and Social Sciences. 2:164-166.

[28] Konuspayeva, G., B. Faye and G. Loiseau. 2009. The composition of camel milk: a meta-analysis of the literature data. Journal of Food Composition and Analysis. 22:95-101.

[29] Konuspayeva, G., B. Faye, G. Loiseau and D. Levieux. 2007. Lactoferrin and immunoglobulin contents in camel's milk (Camelus bactrianus, Camelus dromedarius, and Hybrids) from Kazakhstan. Journal of Dairy Science. 90:38-46.

[30] Konuspayeva, G., E. Lemarie, B. Faye, G. Loiseau and D. Montet. 2008. Fatty acid and cholesterol composition of camel's (Camelus bactrianus, Camelus dromedarius and hybrids) milk in Kazakhstan. Dairy Science \& Technology. 88:327-340.

[31] Kula, J.T. and D. Tegegne. 2016. Chemical composition and medicinal values of camel milk. Int J Res Stud Biosci. 4:13-25.

[32] Mal, G., D.S. Sena, V. Jain and M. Sahani. 2006. Therapeutic value of camel milk as a nutritional supplement for multiple drug resistant (MDR) tuberculosis patients. Israel Journal of Veterinary Medicine. 61:88.

[33] Mona, E., O. Ragia, A. Abeer and T. Mosa. 2010. Biochemical effects of fermented camel milk on diarrhea in rats. New York Science Journal. 3:106-111.

[34] Mullaicharam, A. 2014. A review on medicinal properties of camel milk. World J Pharm Sci. 2:237-42.

[35] Nagy, P. and J. Juhasz. 2016. Review of present knowledge on machine milking and intensive milk production in dromedary camels and future challenges. Tropical animal health and production. 48:915-926.

[36] Omer, R. and A. Eltinay. 2008. Microbial quality of camel's raw milk in central \& southern regions of United Arab Emirates. Emirates Journal of Food and Agriculture.76-83.

[37] Rasheed, Z. 2017. Medicinal values of bioactive constituents of camel milk: A concise report. International journal of health sciences. 11:1.

[38] Raziq, A., M. Younas and M. Kakar. 2008. Camel A potential dairy animal in difficult environments. Pak. J. Agri. Sci. 45:263-267.

[39] Salmen, S.H., H.M. Abu-Tarboush, A.A. Al-Saleh and A.A. Metwalli. 2012. Amino acids content and electrophoretic profile of camel milk casein from different camel breeds in Saudi Arabia. Saudi journal of biological sciences. 19:177-183.

[40] Seifu, E. 2007. Handling, preservation and utilization of camel milk and camel milk products in Shinile and Jijiga Zones, eastern Ethiopia. Marketing. 10:13.7.

[41] Shabo, Y. and R. Yagil. 2005. Etiology of autism and camel milk as therapy. International Journal on Disability and Human Development. 4:67-70.

[42] Sharma, C. and C. Singh. 2014. Therapeutic value of camel milk-a review. Advanced Journal of Pharmacie and Life science Research. 2:7-13.

[43] Shuiep, E.T.S., E. El Zubeir and I.A. Yousif. 2014. Compositional quality of camel milk and some husbandry practices associated with camel milk production in two production systems in Sudan.

[44] Sisay, F. and K. Awoke. 2015. Review on Production, Quality and Use of Camel Milk in Ethiopia. J Fisheries Livest Prod. 3:2.

[45] Stahl, T., H.-P. Sallmann, R. Duehlmeier and U. Wernery. 2006. Selected vitamins and fatty acid patterns in dromedary milk and colostrum. Journal of Camel Practice and Research. 13:53-57.

[46] Usda. 2009. United States Department of Agriculture, National Agricultural Library Dietary Reference Intakes Elements, available at: www.nal.usda.gov.

[47] Wernery, U. 2006. Camel milk, the white gold of the desert. Journal of Camel Practice and Research. 13:15-26.

[48] Worku, S.K. 2015. Economic Contribution of Camel Milk to Pastoralists Livelihood and Assessment of Feed Resource Availability in the Context of Climate Change in Pastoral Areas of Selected Districts of Fafan Zone Eastern Ethiopia. Haramaya University.

[49] Yadav, A.K., R. Kumar, L. Priyadarshini and J. Singh. 2015. Composition and medicinal properties of camel milk: A Review. Asian Journal of Dairy and Food Research. 34:83-91.

[50] Yaqoob, M. and H. Nawaz. 2007. Potential of Pakistani camel for dairy and other uses. Animal Science Journal. 78:467-475. 
[51] Yassin, M.H., M.M. Soliman, S.a.-E. Mostafa and H.a.-M. Ali. 2015. Antimicrobial effects of camel milk against some bacterial pathogens. Journal of Food and Nutrition Research. 3:162-168.

[52] Zhang, H., J. Yao, D. Zhao, H. Liu, J. Li and M. Guo. 2005. Changes in chemical composition of Alxa Bactrian camel milk during lactation. Journal of Dairy Science. 88:3402-3410.

Citation: Adnan Khaliq, et.al, "Camel Milk: Massive Paragon of Nutritional and Therapeutic Potentials: A Review" International Journal of Research Studies In Biosciences (IJRSB), Vol. 7, no. 9, pp. 12-26, 2019. http://Dx.Doi.org/10.20431/2349-0365.0709002

Copyright: (C) 2019 Authors. This is an open-access article distributed under the terms of the Creative Commons Attribution License, which permits unrestricted use, distribution, and reproduction in any medium, provided the original author and source are credited. 